\title{
Migration and child domestic work: Evidence from Ethiopia
}

Annabel Erulkar

Population Council

Follow this and additional works at: https://knowledgecommons.popcouncil.org/departments_sbsr-pgy

Part of the Demography, Population, and Ecology Commons, Family, Life Course, and Society Commons, Gender and Sexuality Commons, International Public Health Commons, and the Migration Studies Commons How does access to this work benefit you? Let us know!

\section{Recommended Citation}

Erulkar, Annabel. 2018. "Migration and child domestic work: Evidence from Ethiopia," brief. Addis Ababa: Population Council. 


\section{MIGRATION AND CHILD DOMESTIC WORK: EVIDENCE FROM ETHIOPIA}

\section{INTRODUCTION}

Child domestic work is one of the most common forms of child labor globally and is considered a form of modern-day slavery (UNICEF 1999; Black 2002). There are an estimated 17.2 million child domestic workers in the world, and the vast majority are girls (ILO 2012). Domestic work keeps children out of school, confined to the home, socially isolated, and burdened with excessive domestic duties (Black 2002). Their time and movements are strictly controlled by their employers. Younger domestic workers are often preferred by employers because they are easier to control and manipulate, and demand little or no pay (HRW 2006).

The International Labour Organization (ILO) Convention 189, "The Domestic Workers Convention," was brought into force in 2013. It calls for normal hours of work for domestic workers, including weekly rest of at least 24 hours and paid annual leave; minimum wage, where one exists for other classes of workers; enforcement of the minimum work age, consistent with other forms of work; a healthy and safe work environment and protection from all forms of abuse, harassment, violence, and more. Only 23 countries have ratified ILO's Convention 189.

The vast majority of child domestic workers in Ethiopia are located in urban areas but originate from poor rural families. One study in Addis Ababa found that 97 percent of domestic workers migrated to the area from rural areas (Erulkar and Mekbib 2007). Domestic workers are significantly less educated than their counterparts who are not in domestic work. In a study in three Ethiopian cities, 49 percent of domestic workers-all of whom were female-had never been to school compared to 13 percent of nondomestic workers (Erulkar and Ferede 2009). The same study found that domestic workers are vulnerable to sexual abuse, and they are nearly twice as likely to experience nonconsensual sex as girls who were not domestic workers. Few programs support girls in domestic work, and awareness of their situation is limited. Therefore, research on the conditions of child domestic work and reasons for girls' entry into this form of work can give program managers critical direction for the design and implementation of context-appropriate support programs.

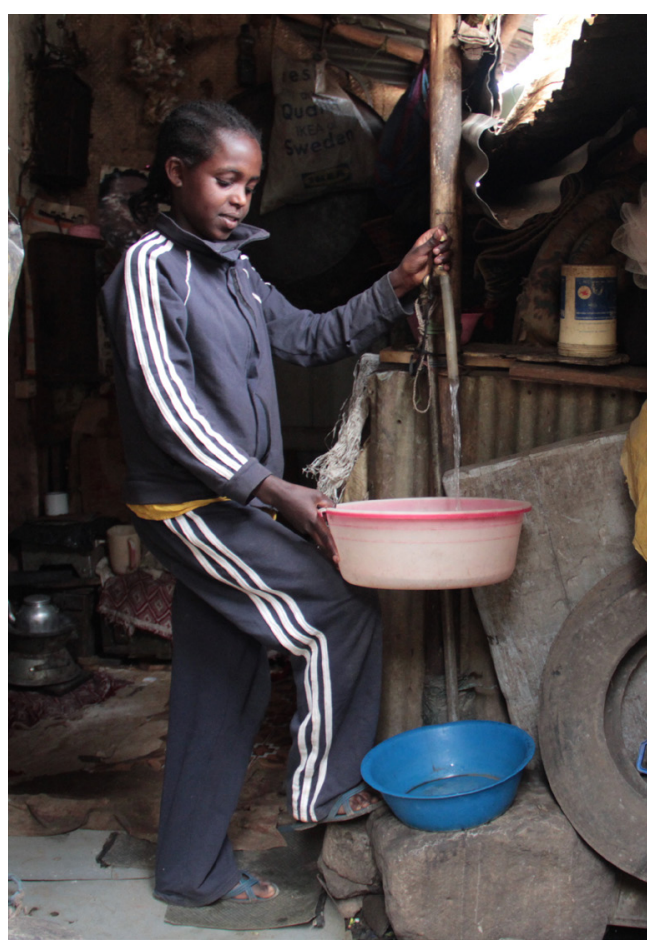

create. change.
POPULATION COUNCIL

Ideas. Evidence. Impact. 
TABLE 1: Conditions of domestic work among current domestic workers $(n=1,094)$

\begin{tabular}{|l|c|}
\hline Age started domestic work (mean) & 15 years \\
\hline Hours in paid work in the last week (mean) & 53 hours \\
\hline Monthly earnings (mean) & 495 Ethiopian Birr (US\$22) \\
\hline Percent who have gotten a job through a broker & 26 percent \\
\hline Amount paid to a broker (mean) & 114 Ethiopian Birr (US\$5) \\
\hline Percent who have no financial support from family or friends & 93 percent \\
\hline Percent who financially support family or friends & 38 percent \\
\hline
\end{tabular}

\section{METHODS}

In 2015-16, the Population Council undertook a study of migrant, out-of-school girls in Ethiopia entitled The Journey of Out-of-School Girls in Ethiopia: Examining Migration, Livelihoods, and HIV (Erulkar, Medhin, and Negeri 2017). The study took place in urban and rural areas in six Ethiopian regions and included both qualitative and quantitative data collection. In the qualitative study, 143 respondents (including 47 domestic workers, as well as migrant girls in other forms of work and commercial sex workers) were interviewed about their life histories, the situation in their rural homes, experiences of migration and transitions to work life in urban areas. The subsequent quantitative survey included interviews with 4,540 urban migrants and 732 rural girls. Among the urban migrants, 1,094 were in domestic work at the time of the survey. Interviews covered a range of topics, including family and educational background, social networks and migration, and livelihoods history.

\section{RESULTS}

Domestic work is frequently the initial survival strategy for rural Ethiopian girls migrating to urban areas. Following migration from rural areas, most girls enter the workforce as domestic workers, because it is a readily available form of work requiring little or no education. Among migrant girls interviewed, 67 percent first enter the work world in domestic work. However, they frequently move into other forms of work, with only 38 percent of migrants still in domestic work in their second position, post-migration. Between their first and second paid work, a significant proportion of girls transition to commercial sex work (from 7 to 17 percent).

Some girls enter domestic work as a preference, while others are lured into work with promises of a better life. The nature of domestic work involves tasks that are familiar to migrant girls from their previous lives in rural areas. Also, some girls initially prefer confinement to the home, because they are unaccustomed to urban areas and particularly dislike harassment from men and boys when working in bars or cafes or when doing errands outside the home.

I actually would rather work as a domestic worker than in a coffee house. As a domestic worker, you only have to concentrate on the housework, but in the coffee house the men try to talk to you and I hate it. -Waitress in Dessie, age 18, migrated at age 15, 5 years of education

My employer does not allow me out. I don't leave the home. If I go out, I return back quickly. I never greet the boys outside.... Until you get married, you have to be careful. You should not joke with anyone. If you joke and get close [to boys], you will be a victim of bad things. -Domestic worker in Mekelle, migrated at age 14,5 years of education

Many domestic workers are encouraged to migrate (39 percent), frequently with false promises and deception by employers in urban areas. Among those who were encouraged, 51 percent were promised a better life, a good job (32 percent), good pay (29 percent), and schooling (10 percent). However, in reality, the conditions of domestic work are frequently exploitive and do not benefit the young worker (Table 1).

Life was difficult and there were a lot of people around. It was nothing like back home. I had to prepare food constantly, and there were so many clothes to wash. They nagged me and only paid me 200 birr [US\$9] per month, which I got every two months. I left that home without even buying one pair of shoes or new clothes. They also withheld 200 birr from my salary when I left. -Assistant cook in Adama, age 18, migrated at age 15, 6 years of education 
Domestic workers reported the lowest monthly earnings compared to girls in other forms of work: an average of 495 Ethiopian Birr (ETB) per month (US\$22), compared to ETB 529 (US\$24) among waitresses and ETB 3,524 (US\$160) among commercial sex workers. A number of girls who were formerly domestic workers reported sexual abuse while in the profession. Few who were currently in domestic work admitted to sexual abuse, possibly because they rely on the employer for housing or shelter and would risk losing their accommodations if reported.

Around four months after I started [domestic work], a relative of the household wanted something from me. He approached me all the time asking for bad things...you know, he wanted sex.... Do you know what day he raped me? It was August 22, around 5 pm. I wanted to shout, but he covered my mouth. I was just a little girl and he was very huge. His hand was the size of my face.... I was a virgin and only 14 years old. -Commercial sex worker, age 18, migrated at age 14, 7 years of education

Domestic workers don't talk about being sexually abused. They don't speak about it. Due to their culture, the probability of them keeping it a secret is high. -Unlicensed broker from Metema, age 32, 9 years of education

\section{RECOMMENDATIONS}

The study demonstrated that domestic work is a common survival strategy for out-of-school migrant girls in Ethiopia upon arrival in urban areas. Originating from poor rural areas and armed with little in the way of education, domestic workers receive low pay and frequently work in abusive situations, including sexual abuse. Several programmatic recommendations arise from this study:

\section{Additional support and HIV prevention programs for migrants and domestic workers}

The conditions of migration and domestic work put girls at risk of sexual abuse, exploitation, and HIV infection. However, these categories of out-of-school girls are largely ignored by HIV prevention efforts. More programs are needed to provide support and safety to migrant girls and domestic workers, especially social assets, information, services, and protection. Programs targeted to the time of migration-when girls are in transit and when they arrive in urban areas-are also recommended as this represents a point of extreme vulnerability for out-ofschool girls.

Programs to address exploitation and abuse of domestic workers

A significant number of former domestic workers described previous experiences of sexual abuse in the context of domestic work. It was also widely believed that domestic workers do not talk about such abuse while still in the profession, but only divulge the information after leaving the profession, largely because they rely on employers for accommodations and risk losing accommodations and the job if abuse is reported. Ethiopia has not ratified the Domestic Workers Convention (C189), which calls for support and protection of domestic workers including enforcement of minimum age of employment, a minimum wage for domestic workers, and decent working hours and conditions, among others (ILO 2012). Programs should raise awareness on the rights of domestic workers and actively promote provisions in the convention.

Provide safe and productive livelihoods skills for out-ofschool girls and women

Out-of-school girls from rural areas are educationally disadvantaged and have limited livelihoods opportunities in urban areas. Support programs should build girls' skills in safe and productive livelihoods, facilitating their exit from unsafe forms of work such as domestic work. Financial literacy and entrepreneurship training can provide out-of-school girls with the skills necessary to transition into safer forms of work, such as petty trade and other small businesses. As well, expanded educational opportunities-including increased access and improvements in quality of education-in both rural and urban areas are important to give girls the grounding necessary to be competitive in the labor force.

\section{Increased attention to trafficking (not just across} international borders)

Much attention has been focused in Ethiopia on the international "maid trade" and cross-border migration, smuggling, and trafficking (UNICEF 2017). Our research suggests that a considerable number of girls within Ethiopia are victims of deception, false promises, and coercion into domestic work, sex work, or other professions, which is tantamount to trafficking (USAID 2012). Domestic workers described being promised schooling in the urban areas or well-paying professional 
jobs, only to find themselves far away from home and anything familiar, working as domestics. Little attention has been paid to such circumstances in the context of internal migration, and increased programmatic attention to internal trafficking, including the role of brokers who find work for migrant girls, is warranted.

\section{REFERENCES}

Black, M. 2002. “Child Domestic Workers: Finding a Voice.” London: Anti-Slavery International.

Erulkar, A. and A. Ferede. 2009. "Social exclusion and early, unwanted sexual initiation in poor urban settings in Ethiopia," International Perspectives on Sexual and Reproductive Health 35(4): 186-193.

Erulkar, A., G. Medhin, and L. Negeri. 2017. "The Journey of Out-of-School Girls in Ethiopia: Examining Migration, Livelihoods, and HIV." Addis Ababa: Population Council. August.

Erulkar, A. and T. Mekbib. 2007. "Invisible and vulnerable: Adolescent domestic workers in Addis Ababa, Ethiopia," Vulnerable Child and Youth Studies 2(3): 246-256.

Human Rights Watch (HRW). 2006. "Swept under the rug: Abuses against domestic workers around the world," Human Rights Watch 18(7).

International Labour Organization (ILO). 2012. "Child

Domestic Work: Global Estimates 2012." Geneva: ILO International Programme on the Elimination of Child Labour (IPEC).

UNICEF. 1999. “Child domestic work," Innocenti Digest. Florence, Italy: UNICEF.

-----. 2017. "A Child Is a Child: Protecting Children on the Move from Violence, Abuse and Exploitation." New York: UNICEF. May.

USAID. 2012. "Counter-Trafficking in Persons Policy." Washington, DC: USAID. February.
This study is made possible by the generous support of the American people through the United States Agency for International Development-President's Emergency Plan for AIDS Relief (USAID-PEPFAR) and the Oak and Novo Foundations. The contents are the responsibility of the authors and do not necessarily reflect the views of USAID or the United States Government, or the Oak or Novo Foundations. 